\title{
O TEMA "CUSTOS" EM PERIÓDICOS DA ENGENHARIA DE PRODUÇÃO: UMA ANÁLISE BIBLIOMÉTRICA E PERSPECTIVAS FUTURAS
}

\section{THE THEME "COST" IN PRODUCTION ENGINEERING JOURNAL: A BIBLIOMETRIC ANALYSIS AND FUTURE PERSPECTIVES}

\author{
Tiago Henrique de Paula Alvarenga ${ }^{1}$; Simone Sartori ${ }^{2}$; Jairo José Assumpção; Lucila Maria de \\ Souza Campos ${ }^{4}$ \\ ${ }^{1}$ Universidade Federal de Santa Catarina (UFSC) - Florianópolis - SC - Brasil \\ thpalvarenga@hotmail.com \\ ${ }^{2}$ Universidade Federal de Santa Catarina (UFSC) - Florianópolis - SC - Brasil \\ simone.sartori@posgrad.ufsc.br \\ ${ }^{3}$ Universidade Federal de Santa Catarina (UFSC) - Florianópolis - SC - Brasil \\ jairo.assumpcao@posgrad.ufsc.br \\ ${ }^{4}$ Universidade Federal de Santa Catarina (UFSC) - Florianópolis - SC - Brasil \\ lucila.campos@ufsc.br
}

\begin{abstract}
Resumo
O objetivo desse artigo é realizar um mapeamento das publicações sobre o tema custos na engenharia de produção e, como consequência, identificar um portfólio bibliográfico das publicações na área. Para atender ao objetivo, fez-se uma análise bibliométrica nos dois principais periódicos brasileiros especializados na área de engenharia de produção (Produção - ISSN 01036513 e Gestão \& Produção - ISSN 0104-530X). Após a busca, foram selecionados 43 artigos relevantes e 540 artigos de referências, que passaram a representar o portfólio bibliográfico. Na análise bibliométrica do portfólio bibliográfico evidencia-se: o autor mais citado "José Luis Duarte Ribeiro"; o artigo com maior reconhecimento científico "Competitividade e coordenação de sistemas agroindustriais: um ensaio conceitual" de Elizabeth M. M. Q. Farina com 130 citações; as palavras-chave mais presentes "custos de transação" e "custos"; o método de pesquisa mais usado é o "estudo de caso" (46\% dos casos são únicos e 54\% são múltiplos). Na análise das referências do portfólio bibliográfico destaca-se: os periódicos "Management Science", "European Journal of Operational Research" e "International Journal of Production Economics"; o autor mais citado "Mohamad Y. Jaber"; em relação ao reconhecimento científico o artigo "Theory of the firm: Managerial behavior, agency costs and ownership structure" de Michael C. Jensen e William H. Meckling, com 44.083 citações. Tal estudo permitiu descobrir as características de publicações do campo e com isso visualizar a evolução científica, os principais autores, os periódicos mais relevantes, as palavras-chave mais utilizadas e características distintivas que integraram os estudos realizados.
\end{abstract}

Palavras-chave: custos; engenharia de produção; análise bibliométrica. 


\section{Introdução}

A presença dos custos no ambiente produtivo das empresas é um fato e sua importância é comprovada nas mais diversas atividades organizacionais como produção, projeto e desenvolvimento, compras, logística/transporte, marketing, vendas, dentre outras. Nesse sentido, o entendimento dos custos é essencial para a execução de praticamente todas as atividades organizacionais, sendo também encarado como um empecilho em determinadas atividades.

$\mathrm{Na}$ atualidade, estratégias com ênfase na redução de custos como downsizing, análise global de valor e reengenharia são amplamente introduzidas nas empresas. Novas tecnologias em equipamentos são adquiridas, funcionários são treinados constantemente, layouts são otimizados, produtos tem seus designs aperfeiçoados, processos são reestruturados e novas metodologias são implantadas (FERREIRA, 2007).

A mensuração dos custos é antiga e surgiu em atendimento às necessidades da administração nas organizações e, desde a época da Revolução Industrial, vem sendo aprimorada como parte do sistema geral de informações. Historicamente, essas necessidades da administração têm sido influenciadas pelo ambiente econômico (CREPALDI, 2004; KHOURY; ANCELEVICZ, 2000).

Em muitas empresas a função contábil tem fracassado por não se adaptar a um novo ambiente competitivo. Em resposta a tais críticas surgiu uma série de procedimentos, inovadores e o aperfeiçoamento de outras já existentes, objetivando suprir as lacunas identificadas pelos profissionais e teóricos da área de contabilidade. Cita-se como exemplo o custeamento baseados em atividades, custeamento por ciclo de vida dos produtos, análise de custos da cadeia de valores e custos de logística interna e de distribuição (RECKZIEGEL; SOUZA; DIEHL, 2007; SOUZA; LISBOA; ROCHA, 2003).

Concomitantemente ao ambiente da contabilidade essa realidade competitiva provocou a introdução de modernas filosofias de administração da produção que também possuem os custos como objeto de estudo, tais como: Just in time (JIT), Gestão da Qualidade Total (TQM), automatização, flexibilidade da produção e produção em células (KHOURY; ANCELEVICZ, 2000).

Tais práticas são defendidas como adequadas e consistentes à nova realidade dos sistemas produtivos das empresas perante aos mercados competitivos e globalizados. Portanto, combinadas às novas exigências, estas objetivam a obtenção e manutenção de vantagens competitivas (SOUZA; LISBOA; ROCHA, 2003).

Levando em consideração os custos no que tange aos sistemas produtivos das organizações, a International Organization for Standardization emitiu normas internacionais sobre sistemas de qualidade: as normas da série ISO 9000. Além de criar parâmetros comuns para facilitar o 
intercâmbio, a normalização também é utilizada como uma estratégia para redução de custos produtivos (SOUZA; COLLAZIOL; DAMACENA, 2010).

Assim, o objetivo deste artigo é realizar um mapeamento das publicações sobre o tema “custos” em relação à área de engenharia de produção. Para isso foi realizado uma análise bibliométrica com a palavra-chave "custos" nos dois principais periódicos brasileiros especializados na área de engenharia de produção (Produção - ISSN 0103-6513 e Gestão \& Produção - ISSN 0104-530X). A escolha deste estudo se deu pelo fato da presença e da importância da gestão de custos para as atividades produtivas das organizações.

\section{Revisão de literatura}

\subsection{A importância dos custos}

O estudo do comportamento dos custos é relevante não unicamente para a academia, mas também para aqueles cuja atuação profissional está diretamente ligada às atividades empresariais. A razão dessa importância incide no fato de que o sustentáculo de muitas decisões gerenciais está no conhecimento de como os custos podem alterar em função do nível de atividade (MEDEIROS; COSTA; SILVA, 2005).

O principal objetivo de se conhecer e de dominar os custos é aumentar a competitividade da empresa através de uma metodologia que determine os custos dos itens comercializados, sua rentabilidade e viabilidade comercial e econômica (FERREIRA, 2007).

Esse domínio dos custos é importante não somente para saber se determinado produto é rentável ou não, como também para indicar se é possível a redução de seus custos de produção. Para que se atinja um resultado satisfatório, é necessário um planejamento que inicie desde a busca do menor preço na aquisição de matéria prima, o uso de mão de obra qualificada até a escolha dos fornecedores que disponham de produtos de boa qualidade e que ofereçam condições favoráveis de pagamento (MCIVOR, 2000; SILVEIRA; BORGES; VELASQUEZ, 2012).

Sendo assim, é relevante frisar a importância do cálculo dos custos para qualquer empresa, seja uma indústria, uma prestadora de serviço ou até mesmo uma cooperativa, pois este cálculo permite definir qual o custo exato do produto vendido ou do serviço prestado, e através disso alcançar uma margem de lucro desejável (SILVEIRA; BORGES; VELASQUEZ, 2012).

Para assegurar o atendimento ao requisito qualidade dos produtos, as empresas têm se dedicado à certificação de sistemas de qualidade por meio do atendimento às determinações das normas ISO. Neste contexto, os custos dão um amparo para que se consiga a certificação da referida norma, pois a mensuração dos custos da qualidade é um requisito obrigatório da certificação (SOUZA; COLLAZIOL, 2006). 
A gestão dos custos da qualidade tem estado, há algumas décadas, inserida na agenda do que se convencionou denominar gestão estratégica de custos. Isso é uma consequência natural do fato de que a gestão da qualidade total também passou a integrar as estratégias empresariais que objetivam assegurar o estabelecimento de vantagens competitivas perante os seus concorrentes (SOUZA; COLLAZIOL, 2006).

A competitividade provocada pela ampla concorrência provocou nas empresas uma corrida para o desenvolvimento e gerenciamento dos custos de seus itens, acentuando cada vez mais a importância de seguir sua evolução, seus respectivos preços de venda e servindo também como orientação nas decisões de permanência ou não destes itens no rol dos produtos comercializados (FERREIRA, 2007). Assim, criou-se a necessidade da gestão de custos com o fim de minimizar os custos e também proporcionar a otimização dos recursos existentes (SILVA et al, 2013).

\subsection{Gestão de custos}

O sistema de custos faz parte de um sistema mais amplo, o de gestão. Dessa forma, o sistema de custos é moldado de acordo com o modelo de gestão existente na organização (BORNIA, 2002). Dessa forma empresas necessitam de um processo sistemático de planejamento, organização, direção e de controle, que se denomina processo de gestão. A área da contabilidade possui uma participação ativa nesse processo de gestão, fornecendo informações de mensuração para praticamente todas as transações empresariais (PADOVEZE, 2006).

Tal processo de gestão auxilia as organizações a gerir com mais eficiência sua cadeia de valor, proporcionando vantagens mercadológicas. Assim, esta conduta por parte das empresas pode acarretar em redução de custos e também diferenciais ao produto final (LOPES et al, 2012).

Com a globalização da economia a gestão de custos se tornou um fator de grande importância para a determinação dos custos como fator estratégico de competitividade. Dessa forma, as empresas são levadas a refletir sobre seus sistemas de custeio e a utilizá-los com finalidades mais gerenciais, uma vez que as informações geradas podem dar suporte à tomada de decisões (DIAS; PADOVEZE, 2007; FINNEY; CAMPBELL; POWELl, 2005).

A gestão de custos, no entanto, está além das técnicas tradicionais da contabilidade. Sob a abordagem contábil, os custos podem ser analisados como Custo Contábil e Custo Gerencial. O Custo Contábil, subordinado à Contabilidade Financeira, está disciplinado por normas legais técnicas (princípios contábeis), fiscais (compulsoriedade na aplicação das leis) e societárias (fatos passados e rigidez formal) (POMPERMAYER; LIMA, 2005).

O Custo Gerencial, embora não vise desrespeitar as leis, não está vinculado a elas. Compromete-se com a eficiência pela redução dos gastos, através de pesquisas e análises voltados 
para a mudança de processos, gestão financeira adequada e para o atendimento de questões especiais relacionadas com a logística do atendimento adequado aos clientes (POMPERMAYER; LIMA, 2005).

Assim, a gestão de custos auxilia os administradores em suas funções gerenciais, por ocupar uma função estratégica no gerenciamento dos produtos. Essa gestão de custos engloba elementos inter-relacionados e interdependentes entre si, que se interagem e se integram, desde as operações necessárias ao custeio, passando por técnicas de registro e acompanhamento, até a análise e gestão de informações (COKINS, 2001; DIAS; PADOVEZE, 2007).

\subsection{Conceitos e classificação de custos}

Assim, a gestão de custos auxilia os administradores em suas funções gerenciais, por ocupar uma função estratégica no gerenciamento dos produtos. Existem vários conceitos sobre custo. Gestores que compreendem estes conceitos são capazes de melhor utilizar as informações e evitar informações distorcidas. Entretanto, há algumas definições de fácil compreensão e que sintetizam a essência deste assunto. A seguir são apresentadas estas definições conforme Ferreira (2007, p.17):

- $\quad$ Custo é um recurso para atingir um objetivo específico;

- $\quad$ Custo é o valor expresso em moeda corrente de atividades materiais efetivamente consumidos e aplicados na fabricação e comercialização de produtos;

- Custo é remuneração dos recursos financeiros, humanos e materiais consumidos na fabricação e comercialização da venda;

- $\quad$ Custo é o preço pelo qual se obtêm um bem.

Em relação ao âmbito da engenharia de produção a definição de Martins (2010) é bastante objetiva ao afirmar que o custo é o gasto necessário para fabricar os produtos da empresa, sendo este o gasto relativo ao bem ou serviço utilizado na produção de outros bens ou serviços.

Para Leone e Leone (2012), os custos dos produtos ou serviços são formados por três fatores, sendo estes os materiais para a elaboração dos produtos, a mão-de-obra necessária para a fabricação dos produtos/serviços e os demais recursos fabris ou de realização dos serviços. Segundo os autores, esses são os fatores básicos que podem ser detalhados para facilitar o cálculo dos custos.

Para uma melhor compreensão dos custos a Figura 1, apresenta as principais classificações de custos presentes na literatura:

Figura 1 - Classificações de custos 


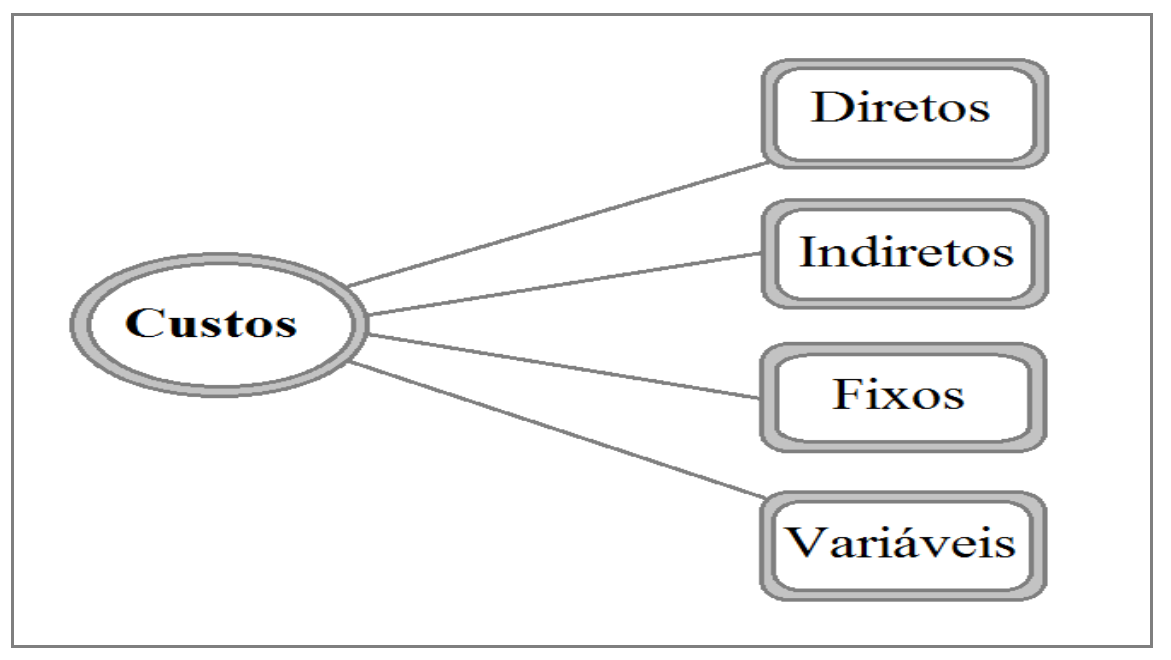

Fonte: Adaptado de Dias e Padoveze (2007)

Os custos podem ser classificados como diretos, indiretos, fixos e variáveis. Os custos são diretos quando são inteiramente apropriáveis ao produto/serviço. (DIAS; PADOVEZE, 2007). São aqueles podem ser facilmente identificados com o objeto de custeio (MARTINS, 2010).

Os custos indiretos são aqueles que são apropriáveis ao produto mediante rateio ou estimativas (DIAS; PADOVEZE, 2007). São os outros custos que realmente não oferecem uma condição de medida objetiva e qualquer tentativa de alocação tem de ser feita de maneira estimada e muitas vezes arbitrária, como aluguel, a supervisão, as chefias, entre outros (MARTINS, 2010).

Os custos fixos são aqueles que tendem a permanecer constantes nas alterações do volume das atividades operacionais, mesmo que qualquer custo esteja sujeito à mudanças ao longo do tempo. Em resumo, são os custos necessários para manter um nível mínimo de atividade operacional dentro de um intervalo de produção e venda (PADOVEZE, 2006). Os custos fixos podem ser exemplificados através dos salários pagos aos funcionários (MARTINS, 2010).

Os custos variáveis são aqueles que em um dado período apresentam variação. São todos os elementos que sofrem variação em relação ao volume produzido (MARTINS, 2010).

Dessa forma, para que as organizações se mantenham no mercado estas necessitam realizar suas atividades e vender seus produtos, mas estas jamais poderão ser realizadas sem que para isso se gaste ou se aplique capitais. Assim, os custos são os gastos que são aplicados na produção, onde o seu resultado é o produto/serviço (LOPES de SÁ, 2009).

\section{Procedimentos metodológicos}

A investigação do tema de pesquisa - custos na engenharia de produção - enquadra-se como exploratória e bibliográfica. A pesquisa é do tipo exploratória uma vez que se propõe a formular questões e propiciar as condições para os autores aprenderem e encontrarem as respostas 
(LAKATOS; MARCONI, 2005). A pesquisa bibliográfica é elaborada a partir de material já publicado (GIL, 2010). A bibliografia oferece meios para definir, resolver, não somente problemas já conhecidos, como também explorar novas áreas (TRUJILLO, 1974).

Esta pesquisa é composta por duas etapas principais: (i) identificação e seleção de um portfólio de artigos; e, (ii) análise bibliométrica do portfólio. Assim, será construído o conhecimento necessário acerca do tema pesquisado.

Neste estudo, foi considerada a análise das publicações nos dois principais periódicos brasileiros especializados na área de engenharia de produção, o periódico "Produção" (ISSN 01036513) e "Gestão \& Produção" (ISSN 0104-530X), como elementos centrais por sua abrangência e relevância e por refletirem o estado da arte da pesquisa brasileira na área de custos.

Inicialmente, os artigos científicos foram identificados por meio de uma pesquisa estruturada por palavras-chave na base de dados SCIELO. As palavras-chave do tipo custo (cost) foram combinadas com engenharia de produção e produção (production engineering e production). Dessa forma, a ocorrência das mesmas em título, resumo e palavras-chave foi conduzida para a definição do portfólio de artigos alinhados ao tema da pesquisa. Não houve delimitação temporal das publicações. O software utilizado para o registro e seleção dos artigos foi o Excel.

$\mathrm{Na}$ fase seguinte procedeu-se a análise bibliométrica, dividida em três etapas de análise: (i) dos artigos da amostra, (ii) das referências citadas por eles e, (iii) da relevância acadêmica dos trabalhos do referencial teórico. Na primeira etapa, avaliou-se o tipo de pesquisa, as palavras-chave mais utilizadas e os autores de destaque. Na segunda etapa, além de destacar os autores que formam as referências do portfólio, foi determinado os periódicos de destaque.

Finalmente, na terceira etapa, foi determinada a relevância acadêmica dos artigos por meio do número de citações no Google acadêmico. Ressalta-se que, para análise bibliométrica, foi composta pelo seguinte conjunto de dados: 43 artigos que formam o portfólio bibliográfico e 540 artigos das referências bibliográficas do tipo artigo encontradas nos artigos do portfólio bibliográfico. Os resultados são apresentados por meio de gráficos que especificam as ocorrências das variáveis estudadas.

\section{Resultados e discussões}

A análise bibliométrica sobre os artigos que formaram o portfólio bibliográfico tem como objetivo desenvolver um maior entendimento a respeito do tema custos na engenharia de produção em termos da seleção dos mais destacados artigos, autores, palavras-chave e periódicos que formam as referências. Com esse propósito, passamos a discutir os resultados obtidos pela análise bibliométrica. 
A primeira análise apresenta a distribuição dos artigos em relação ao método de pesquisa adotado, conforme a tipologia de Berto e Nakano (2000), conforme a figura 2:

Figura 2 - Frequência de trabalhos de pesquisa por tipo de pesquisa

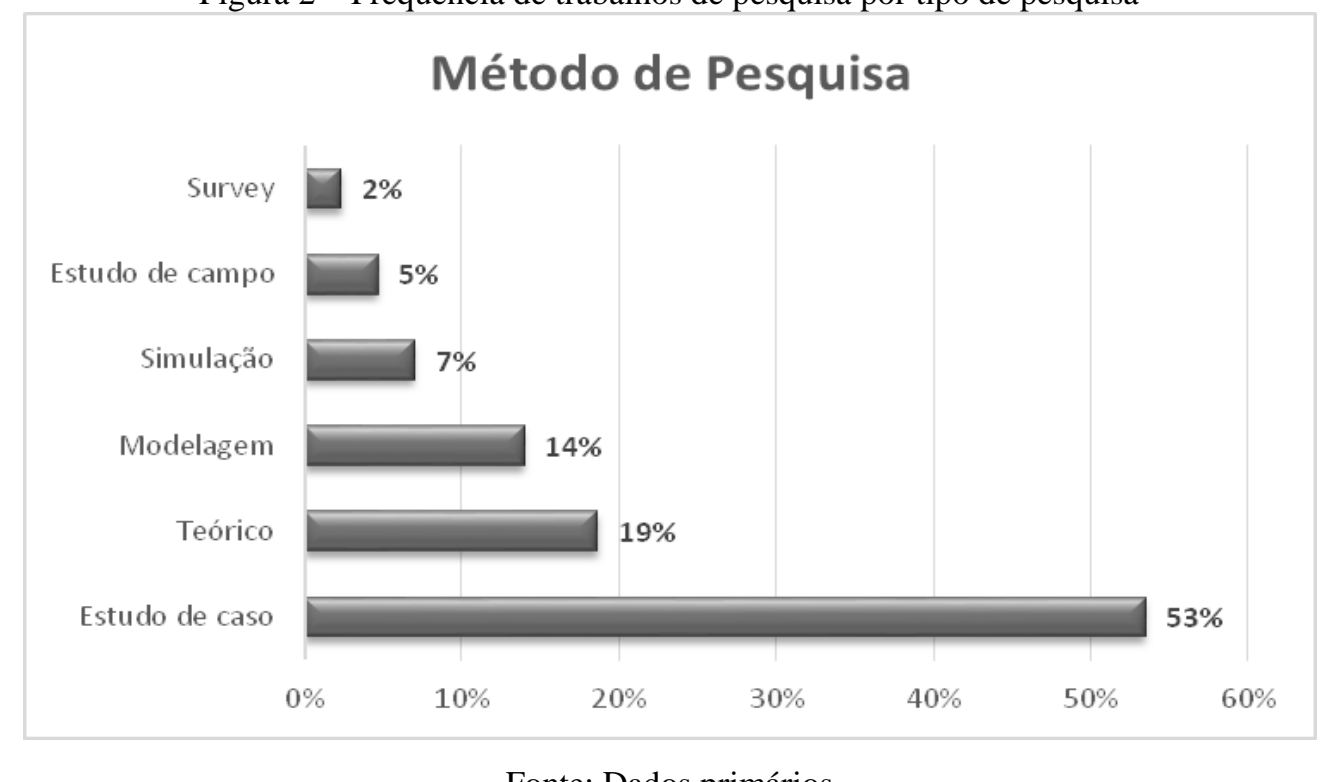

Fonte: Dados primários

Ao se analisar a Figura 2 nota-se que 53\% dos trabalhos pesquisados utilizam como método de pesquisa o estudo de caso, ou seja, uma análise aprofundada de um ou mais objetos e com a interação entre o pesquisador e o objeto de análise em situações reais.

Cabe ressaltar que em alguns trabalhos, foram identificados a utilização de abordagens combinadas, sendo considerado, para o efeito do estudo, o método predominante de cada estudo. Tratando especificamente dos estudos de caso, verifica-se que $46 \%$ dos casos são únicos, ao passo que 54\% são múltiplos. O interesse pelos casos múltiplos se deve ao fato de haver maior interesse em pesquisar fatores que são comuns (ou não) a todos os casos no grupo escolhido ou fatores que são únicos num caso específico. Além disso, destaca-se que os métodos do tipo teórico (19\%) e modelagem (14\%). 
Os estudos teóricos limitam-se a discussões conceituais a partir da literatura e revisões bibliográficas; já os de modelagem fazem uso de técnicas matemáticas para descrever o funcionamento de um sistema (NAKANO, 2012).

A segunda análise apresenta o grau de relevância dos autores do portfólio bibliográfico e das referências do portfólio bibliográfico. Portanto, dentre os 97 autores do portfólio bibliográfico analisado, destacam-se: (i) o autor José Luis Duarte Ribeiro por ter contribuído com a participação em três trabalhos do portfólio; e, (ii) os autores Hugo T.Y. Yoshizaki, José C. de Toledo, José G.V. Vieira, Mário O. Batalha, Peter Wanke, Reinaldo Morabito, que possuem dois trabalhos cada no portfólio. Os demais 90 autores participaram com apenas um artigo no portfólio.

A seguir, foram identificados os autores de destaque dentre os 796 autores das referências dos artigos do portfólio bibliográfico. Como resultado, o autor de maior relevância é Mohamad Y. Jaber com 14 artigos publicados, conforme a Figura 3:

Figura 3 - Autores de destaque nas referências do portfólio bibliográfico

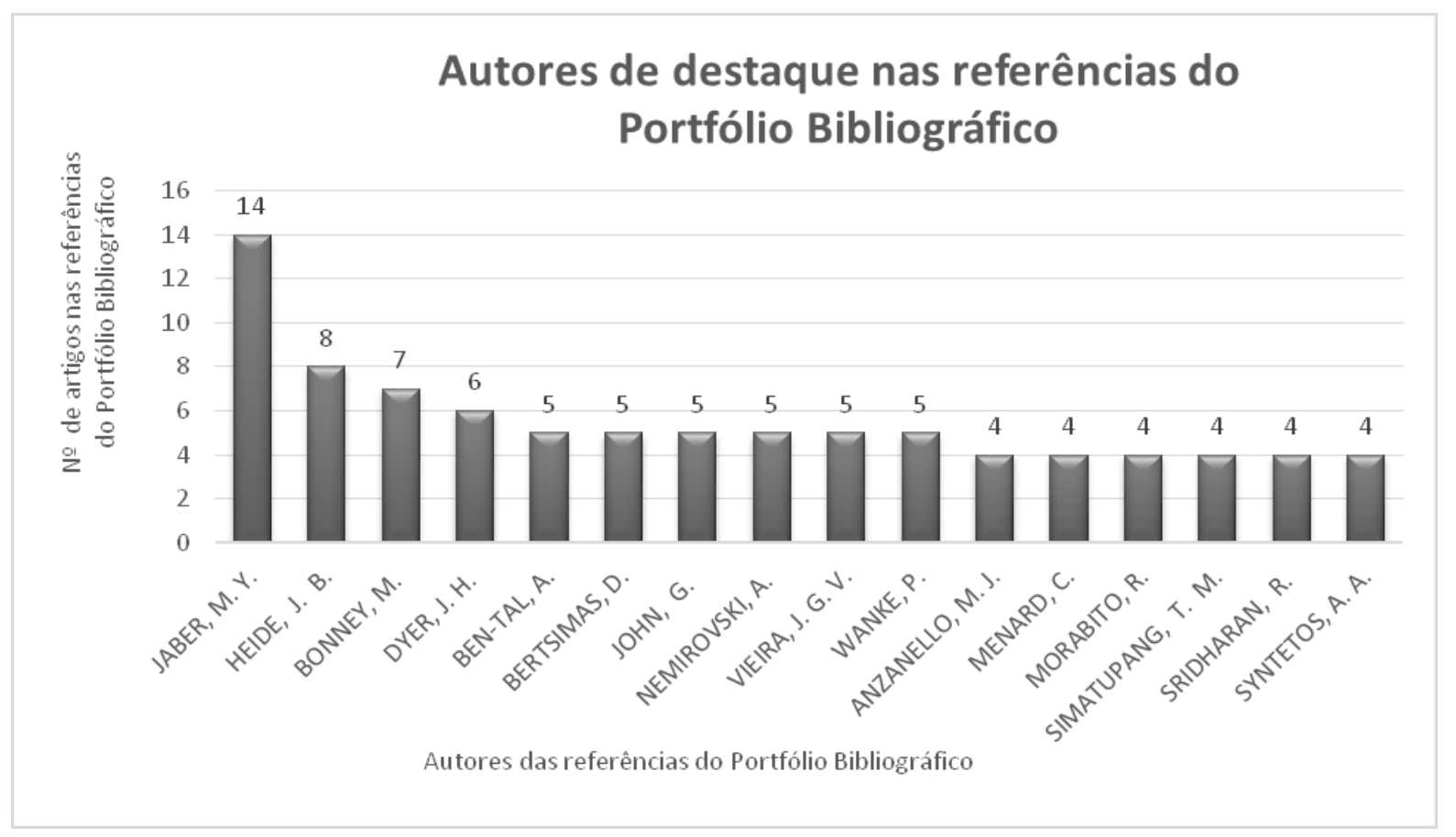

Fonte: Dados primários

A terceira análise busca estimar o grau de relevância dos periódicos. O portfólio bibliográfico é formado por dois periódicos de destaque na Engenharia de Produção, sendo que: (i) 25 artigos fazem parte do periódico "Gestão \& Produção"; e, (ii) 18 artigos fazem parte do periódico "Produção". Destaca-se que esses periódicos, além de fornecer um meio de comunicação para pesquisas acadêmicas na área de Engenharia de Produção, despertam o interesse da comunidade empresarial, pois visam apresentar casos e situações de empresas provenientes de estudos reais ou mesmo de experiências. 
$\mathrm{Na}$ sequência, foram identificados os periódicos com o maior número de artigos nas referências do portfólio bibliográfico. As referências dos artigos foram publicadas em 216 diferentes periódicos, e destacam-se os periódicos Management Science com 23 artigos, European Journal of Operational Research com 22 artigos e International Journal of Production Economics com 21 artigos (Figura 4):

Figura 4 - Relevância dos periódicos nas referências dos artigos do portfólio bibliográfico

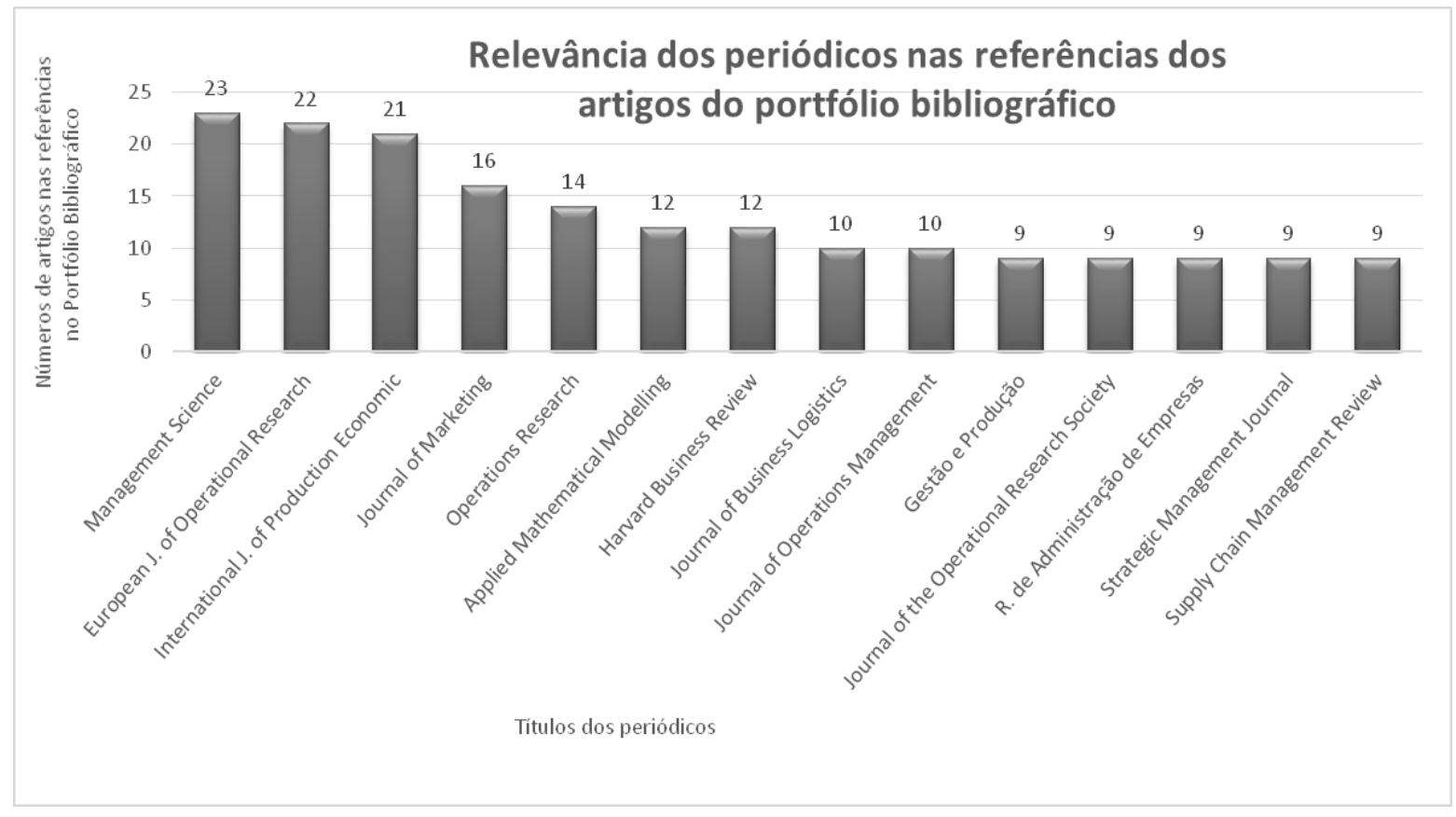

Fonte: Dados primários

O periódico de destaque Management Science, criado em 1954, publica pesquisas científicas relacionadas à prática da gestão. Dentro desse escopo estão todos os aspectos de gestão relacionados com a estratégia, empreendedorismo, inovação, tecnologia da informação, bem como todas as áreas funcionais da empresa, tais como contabilidade, finanças, marketing e operações. Ressalta-se que o periódico estimula pesquisas em áreas emergentes, formadas pela globalização econômica, mudanças de políticas públicas, melhorias tecnológicas e tendências na prática de gestão. 
A quarta análise apresenta o grau de reconhecimento científico dos artigos do portfólio e das referências do portfólio. Para fins dessa análise, entende-se por reconhecimento científico de um artigo como sendo o número de citações encontradas para o artigo após consulta ao Google Scholar (SARTORI et al., 2014). Portanto, ao avaliar o reconhecimento científico dos artigos do portfólio bibliográfico (pesquisa realizada em 21 de julho de 2014), evidenciam-se os artigos: Competitividade e coordenação de sistemas agroindustriais: um ensaio conceitual, de Elizabeth M.M.Q. Farina, com 130 citações; seguido pelo artigo Sistemas ERP: características, custos e tendências de Thais C.C. Padilha e Fernando A.S. Marins com 46 citações. Os dois artigos são de cunho teórico.

Posteriormente, foi identificado o reconhecimento científico das referências presentes nos artigos do portfólio bibliográfico. Destacam-se, nessa etapa, os artigos: (i) Theory of the firm: Managerial behavior, agency costs and ownership structure de Michael C. Jensen e William H. Meckling, com 44.083 citações; (i) The Competitive Advantage of Nations de Michael E. Porter, com 30.807 citações; e, (iii) The nature of the firm de Ronald H. Coase, com 27.079 citações.

A quinta análise buscou estimar as palavras-chave mais utilizadas nos artigos que formam o portfólio bibliográfico. Foram identificadas 143 palavras-chaves utilizadas 184 vezes no portfólio de artigos. Desse total, quatro palavras chaves foram utilizadas três vezes ou mais, evidenciando-se que as palavras-chave mais utilizadas foram "custos de transação" aparecendo nove vezes e “custos”, aparecendo oito vezes no portfólio de artigos. Se isolarmos a expressão custos de expressões combinadas, como por exemplo custos de transporte ou custos hospitalares pode-se identificar que a expressão é recorrente em trinta e sete vezes representando $20 \%$ do total de palavras chaves utilizadas. A Figura 5 apresenta esses dados:

Figura 5 - Palavras-chave mais utilizadas no Portfólio Bibliográfico 


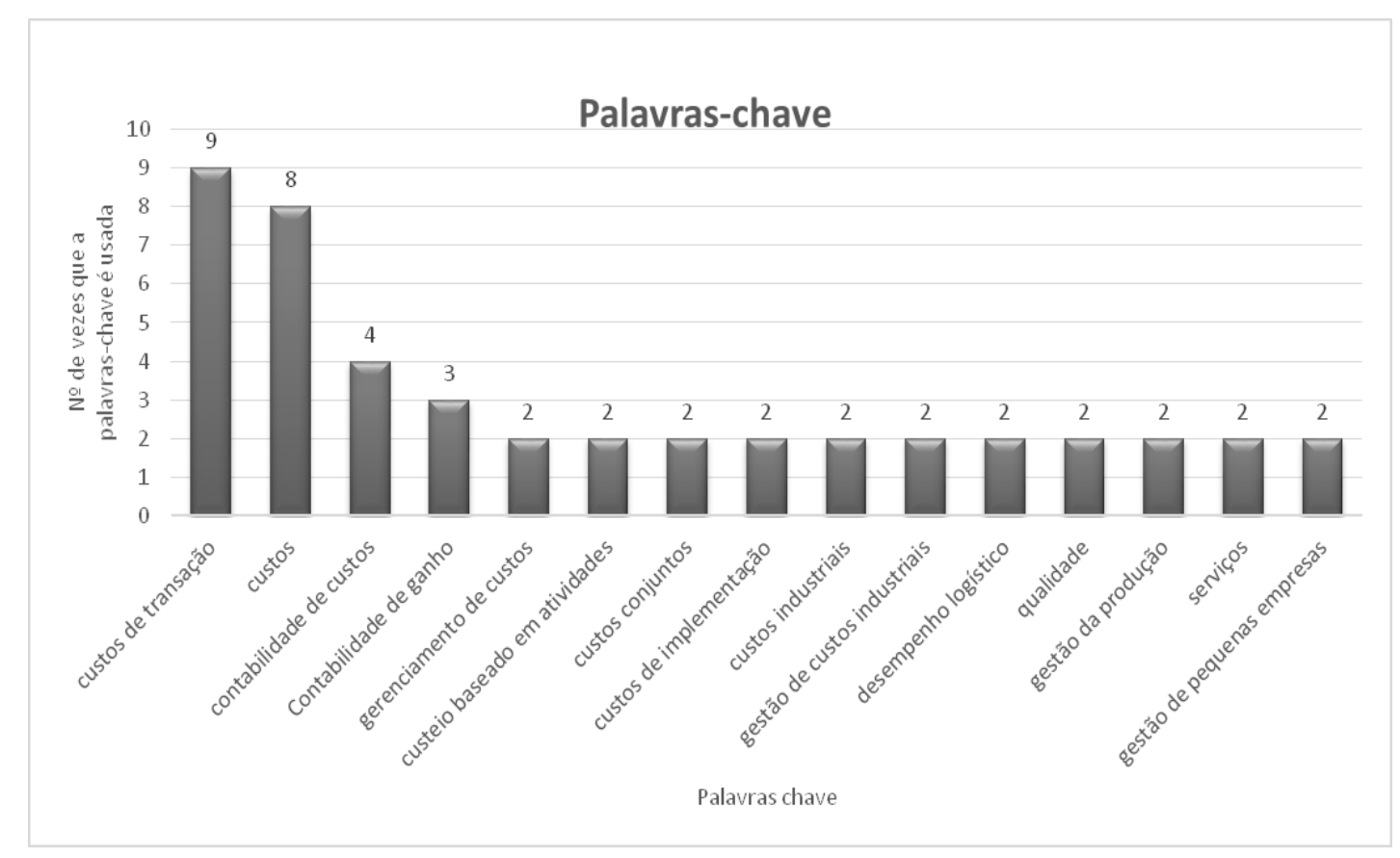

Fonte: Dados primários

A sexta análise apresenta a distribuição temporal dos artigos do portfólio (linha verde) e das referências do portfólio bibliográfico (linha vermelha), conforme Figura 6. As primeiras pesquisas sobre custos na engenharia de produção ocorrem no início da década de 90, e apresenta um pequeno crescimento no período. Internacionalmente, as pesquisas iniciaram em 1913 com elevado crescimento a partir de meados da década de 80. A Figura 6 apresenta esta distribuição:

Figura 6 - Distribuição temporal dos artigos do portfólio e das referências do portfólio 


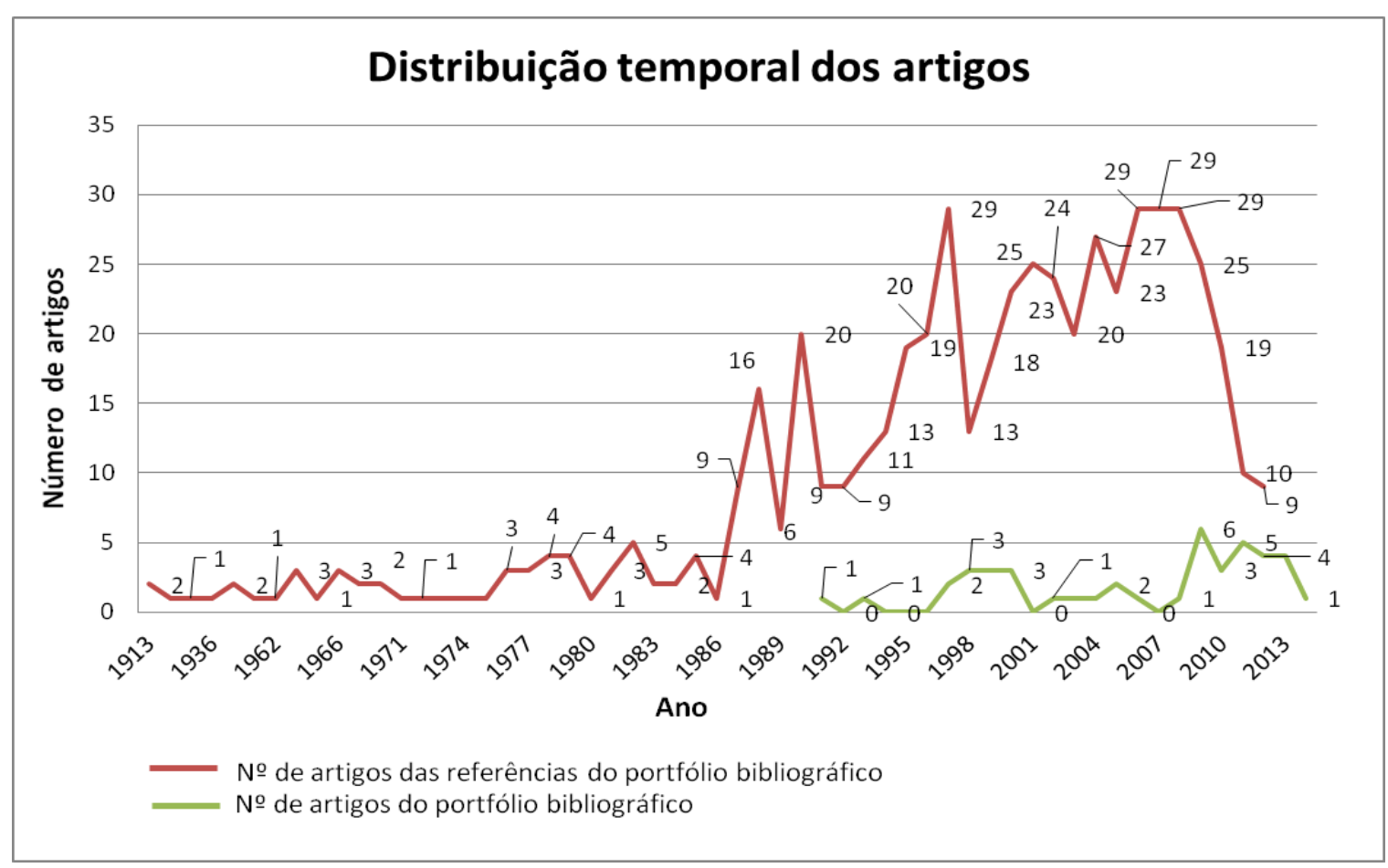

Fonte: Dados primários

Desde o século passado a divulgação de pesquisas em periódicos representa o principal meio de comunicação (REGO, 2014). Em sua grande maioria, os periódicos têm como missão a comunicação dos resultados de pesquisas originais que contribuem para o avanço do conhecimento nas disciplinas ou áreas temáticas específicas. Em alguns campos de pesquisa, os periódicos não são o principal meio de divulgação do conhecimento científico, conforme aponta o estudo de Packer (2011). Conforme esse autor, os periódicos predominam nas ciências da saúde (86\% das citações), ciências biológicas (85\%), ciências exatas e da terra (79\%), ciências agrárias (72\%) e engenharias $(69 \%)$.

Conforme Van Raan (2005), os pesquisadores, e em particular nas ciências naturais e área médica, divulgam seus trabalhos nos melhores periódicos. Uma situação semelhante está se desenvolvendo no campo das ciências sociais e comportamentais, também mais especificamente na engenharia, e, em menor grau, na área de humanas.

De modo geral, no Brasil o conhecimento é construído principalmente nos cursos de pósgraduação por meio da divulgação de pesquisas em temas emergentes. Nesse sentido, o fundamento da abordagem bibliométrica para avaliar o tema custos na engenharia de produção representa o progresso científico, e consequentemente o aumento substancial de informações para a construção do conhecimento acerca do tema.

Destaca-se, que são vários os fatores que podem influenciar a produtividade científica, como por exemplo a estrutura e organização dos grupos científicos, os critérios de seleção de acesso à educação de pós-graduação, bem como, os subsídios e financiamentos à pesquisa. 
Conforme os resultados apresentados evidenciam-se o comprometimento da Engenharia de Produção em relação ao tema custos. Ademais, os custos são objetos de estudo nos mais distintos setores, assim, torna-se fonte de estudos e de descobertas em relação a este assunto.

\section{Conclusões}

A análise bibliométrica é um ponto de partida no que diz respeito às características da ciência na área de engenharia de produção e custos. Nesse sentido, a análise bibliométrica do portfólio bibliográfico consistiu na inferência estatística do conjunto de artigos para a estruturação de um quadro de informação e doe conhecimento científico acerca do tema pesquisado.

Nesse sentido a bibliometria permitiu descobrir as características de publicações do campo e com isso visualizar a evolução científica, os principais autores, os periódicos mais relevantes, as palavras-chave mais utilizadas e características distintivas que integraram os estudos realizados. Por mais que o progresso científico do tema em questão avaliado nesse artigo não seja completo, dada as delimitações definidas pelos autores, a análise bibliométrica foi baseada na ideia central de que a seleção e análise das informações permitem a construção do conhecimento. Assim, a utilização de indicadores bibliométricos torna-se uma estratégia para conseguir uma análise mais equilibrada e, portanto, mais objetiva do objeto estudado.

Como direcionamento de pesquisas futuras no âmbito da Engenharia de Produção, houve um entendimento que o aprofundamento da análise de custos utilizando os métodos mais recorrentes emerge como um campo fértil. A escolha de um método de custeio é fundamental para casos em que as empresas decidem competir com base em custos e também quando há otimização dos processos.

Nesse sentido cada método de custeio fornece informações relevantes à administração dos negócios e não se trata de opções mutuamente excludentes, pois a empresa pode utilizar todos os métodos de custeio para fins gerenciais, o que potencializa a relevância para pesquisas futuras.

Por fim, a história do mapeamento da ciência é relativamente curta e algumas pessoas ou poucos grupos têm se empenhado com a aplicação de estudos bibliométricos. Assim, como propostas para pesquisas futuras, sugere-se a ampliação da análise bibliométrica nas mais diversas fontes de comunicação e publicação científica como periódicos, congressos e patentes.

\footnotetext{
Abstract

The purpose of this article is to map the publications on the topic costs in production engineering and, as a consequence, identify a bibliographic portfolio of publications in the area. To meet the goal, there was a bibliometric analysis in the two major Brazilian journals specialized in the production of engineering (Production - ISSN 0103-6513 and Management \& Production - ISSN 0104-530X). After the search, it was selected 43 relevant articles and 540 references of articles,
} 
which accounted for the bibliographic portfolio. In bibliometric analysis of bibliographic portfolio is evident: the most cited author "José Luis Duarte Ribeiro"; Article more scientific recognition "Competitiveness and coordination of agribusiness systems: a conceptual essay" Elizabeth MMQ Farina with 130 citations; the most present keywords "transaction costs" and "costs"; the most widely used research method is the "case study" (46\% of cases are unique and 54\% are multiple). In the analysis of the bibliographic references portfolio stands out: Periodicals "Management Science", "European Journal of Operational Research" and "International Journal of Production Economics"; the most cited author "Mohamad Y. Jaber"; on the scientific recognition from the "Theory of the firm: Managerial behavior, agency costs and ownership structure" Michael C. Jensen and William H. Meckling, with 44,083 citations. This study allowed to discover the field of publications and features with this view of scientific progress, the main authors, the most relevant journals, the most used keywords and distinctive features that have integrated studies.

Key-words: costs; production engineering; bibliometric analysis.

\section{Referências}

BERTO, R. M. V. S.; NAKANO, D.N. A produção científica nos anais do encontro nacional de engenharia de produção: um levantamento de métodos e tipos de pesquisa. Produção, v.9, n.2, p. 65-76. crossref

COKINS, G. Measuring costs across the supply chain. Cost Engineering, v.43, n.10, p. 25-31. 2001.

CREPALDI, S. A. Curso básico de contabilidade de custos. São Paulo: Atlas, 2004.

DIAS, E. A.; PADOVEZE, C. L. Os diferentes métodos de custeio e sua implicação na apuração de custo do produto: um estudo caso em empresa de graxas e óleos industriais. Revista Eletrônica Gestão e Sociedade, v.1, n.2, p.1-21, jul/dez. 2007. Disponível em: < http://www.gestaoesociedade.org/gestaoesociedade/article/view/564/547 > Acesso em: 1 jul. 2014.

FERREIRA, J. A. Custos industriais: uma ênfase gerencial. São Paulo: Editora STS. 2007.

FINNEY, R. Z.; CAMPBELL, N. D.; POWELL, C. M. Strategies and resources: pathways to success? Journal of Business Research, v.58, n.12, p.1721-1729. 2005. crossref

KHOURY, C. Y.; ANCELEVICZ, J. Controvérsias acerca do sistema de custos ABC. Revista de Administração de Empresas - RAE FGV, v.40, n.1, p.56-62, jan/mar. 2000.

LEONE, G. S. G.; LEONE, R. J. G. Curso de contabilidade de custos. São Paulo: Atlas, 2012.

LOPES de SÁ, A. Tecnologia contábil contemporânea. Curitiba: Juruá. 2009.

LOPES. L. C. et al. Divulgação voluntária da cadeia de valor nos relatórios financeiros de empresas brasileiras de capital aberto. Sociedade, Contabilidade e Gestão - UFRJ, v.7, n.2, jul/dez. 2012.

MARTINS, E. Contabilidade de custos. São Paulo: Atlas, 2010.

MCIVOR, R. A practical framework for understanding the outsourcing process. Supply Chain Management: An International Journal, v.5, n.1, p.22-36, 2000. crossref

MEDEIROS, O. R.; COSTA, P. S.; SILVA, C. A. T. Testes empíricos sobre o comportamento assimétrico dos custos nas empresas brasileiras. Revista Contabilidade \& Finanças - USP, n.38, p.47-56, mai/ago. 2005.

NAKANO, D.N. Métodos de Pesquisa Adotados na Engenharia de Produção e Gestão de Operações. In: CAUCHICK MIGUEL, P.A (Org.). Metodologia de pesquisa em engenharia de produção e gestão de operações. Rio de Janeiro: Elsevier. 2012.

PADOVEZE, C. L. Introdução à contabilidade: com abordagem para não contadores. São Paulo: Pioneira Thomson Learning. 2006. 
POMPERMAYER, C. B.; LIMA, J. E. P. Gestão de Custos. In: Judas Tadeu Grassi Mendes; Christian Luiz da Silva. (Org.). Gestão Integrada de Negócios - Teorias e Práticas para o Sucesso Empresarial. Rio de Janeiro: Forense, 2005, cap.4, p.49-58.

RECKZIEGEL, V.; SOUZA, M. A.; DIEHL, C. A. Práticas de Gestão de Custos adotadas por empresas estabelecidas nas regiões noroeste e oeste do Estado do Paraná. Revista Brasileira de Gestão de Negócios. v.9, n.23, p.14-27, 2007.

REGO, T. C. Produtivismo, pesquisa e comunicação científica: entre o veneno e o remédio. Educação e Pesquisa, v.40, n.2, p.325-346, 2014. crossref

SARTORI, S.; ENSSLIN, L.; SOUZA CAMPOS, L. M.; ENSSLIN, S. R. Mapeamento do estado da arte do tema sustentabilidade ambiental direcionado para a tecnologia de informação. TransInformação, v.26, n.1, p.77-89, 2014. crossref

SILVA, E. M. et al. Método de Custeio de Instituições Federais de Ensino Superior: a Metodologia do Tribunal de Contas da União \& Metodologia do MEC. Revista ADMpg - Gestão Estratégica, v.6, n.1, p.97-105, 2013.

SILVEIRA, A. O.; BORGES, A. P. M.; VELASQUEZ, M. D. P. Gestão de custos no setor açougue de uma cooperativa de consumo. ABCustos, v.7, n.3, p.1-24, set/dez. 2012.

SOUZA, M. A.; COLLAZIOL, E. Planejamento e controle dos custos da qualidade: uma investigação da prática empresarial. Revista Contabilidade \& Finanças - USP, n.41, p.37-55, mai/ago. 2006.

SOUZA, M. A.; COLLAZIOL, E.; DAMACENA, C. Mensuração e registro dos custos da qualidade: uma investigação das práticas e da percepção empresarial. Revista de Administração Mackenzie - RAM, v.11, v.4, p.66-97, jul/ago. 2010 .

SOUZA, M. A.; LISBOA, L. P.; ROCHA, W. Práticas de contabilidade gerencial adotadas por subsidiárias brasileiras de empresas multinacionais. Revista Contabilidade \& Finanças - USP, n.32, p.40-57, mai/ago. 2003.

VAN RAAN, A.F.J. Measurement of central aspects of scientific research: Performance, interdisciplinarity, structure. Measurement: Interdisciplinary Research and Perspectives, v.3, n.1, p.1-19, 2005. crossref

\section{Apêndice A - Relação do portfólio de artigos utilizado na pesquisa}

\begin{tabular}{ll}
\hline \multicolumn{1}{c}{ Autores/Ano } & \multicolumn{1}{c}{ Título } \\
\hline Plonski et al. (1991) & Gestão de projetos industriais baseada em análise de custos \\
\hline Pamplona (1993) & $\begin{array}{l}\text { As inadequações do sistema tradicional de custos em um novo ambiente de } \\
\text { fabricação }\end{array}$ \\
\hline Fleury et al. (1997) & $\begin{array}{l}\text { Em busca da eficiência no transporte terceirizado: estrutura de custos, parcerias e } \\
\text { eliminação de desperdícios. }\end{array}$ \\
\hline Ribeiro et al. (1997) & Otimização da Formulação de uma Mistura Parte 2: Custo \\
\hline Bialoskorski Neto; & $\begin{array}{l}\text { Agroindústria cooperativa: um ensaio sobre crescimento e } \\
\text { estrutura de capital }\end{array}$ \\
\hline Marques (1998) & $\begin{array}{l}\text { Sistemas de custeio para firmas agroalimentares: o caso dos } \\
\text { laticínios e empresas processadoras de soja no Brasil }\end{array}$ \\
\hline Scramim; Batalha (1998) & Custos da qualidade: diagnóstico nas empresas com certificação ISO 9000 \\
\hline Pizzolato et al. (1999) & $\begin{array}{l}\text { O problema do sequenciamento da produção em uma indústria química: avaliação } \\
\text { de uma aplicação real }\end{array}$ \\
\hline Almeida; Brunstein (1999) & Gestão de custos florestais: um estudo de caso utilizando o activity-based costing \\
\hline Farina (1999) & Competitividade e coordenação de sistemas agroindustriais: um ensaio conceitual \\
\hline $\begin{array}{l}\text { Ribeiro; Caixeta Filho } \\
\text { (2000) }\end{array}$ & $\begin{array}{l}\text { Coordenação vertical do transporte de madeira: } \\
\text { análise empírica dos arranjos institucionais existentes na } \\
\text { indústria brasileira de celulose }\end{array}$ \\
\hline Duran; Radaelli (2000) & Metodologia ABC: implantação numa microempresa \\
\hline Sonda et al. (2000) & A aplicação do QFD no Desenvolvimento de Software: Um Estudo de Caso \\
\hline Silva; Ribeiro (2002) & Uma proposta para a modelagem do valor percebido na prestação de serviços \\
\hline Callado et al. (2003) & $\begin{array}{l}\text { Fatores associados à Gestão de Custos: um estudo nas micro e pequenas empresas } \\
\text { do setor de confecções }\end{array}$ \\
\hline Cabral (2004) & $\begin{array}{l}\text { Analisando a reconfiguração da cadeia de produção de pneus no Brasil pela } \\
\text { economia dos custos de transação }\end{array}$ \\
\hline &
\end{tabular}




\begin{tabular}{|c|c|}
\hline Padilha; Marins (2005) & Sistemas ERP: características, custos e tendências \\
\hline Santos; Jesus (2005) & $\begin{array}{l}\text { Fatores que comprometem a adoção de tecnologia de informação em empresas } \\
\text { cafeeiras }\end{array}$ \\
\hline Cassel et al. (2006) & $\begin{array}{l}\text { Maximização da lucratividade em produção conjunta: um caso na indústria } \\
\text { frigorífica }\end{array}$ \\
\hline Marin-Garcia et al. (2008) & $\begin{array}{l}\text { Análisis de programas de mejora continua. Un estudio longitudinal en una empresa } \\
\text { industrial }\end{array}$ \\
\hline Lacerda et al. (2009) & $\begin{array}{l}\text { Uma abordagem de avaliação de processos baseados no mundo dos custos para } \\
\text { processos no mundo dos ganhos em instituições de ensino superior }\end{array}$ \\
\hline Vieira et al. (2009) & $\begin{array}{l}\text { Um estudo sobre colaboração logística entre indústria de bens de consumo e redes } \\
\text { de varejo supermercadista }\end{array}$ \\
\hline Aymard; Brito (2009) & Custos de Mudança em serviços logísticos \\
\hline Piekarski; Cziulik (2009) & $\begin{array}{l}\text { Modelo para avaliação econômica comparativa entre alternativas de sistemas de } \\
\text { fixação com elementos roscados }\end{array}$ \\
\hline Bezerra et al. (2009) & $\begin{array}{l}\text { Análise e caracterização de modelos de custos que utilizam o } \\
\text { valor de Shapley para alocação de custos entre departamentos }\end{array}$ \\
\hline Sinisgalli et al. (2009) & $\begin{array}{l}\text { O custeio ABC e a contabilidade de ganhos na definição do mix de produção de } \\
\text { uma metalúrgica }\end{array}$ \\
\hline Queiroz; Rentes (2010) & $\begin{array}{l}\text { Contabilidade de custos vs. contabilidade de ganhos: respostas às exigências da } \\
\text { produção enxuta }\end{array}$ \\
\hline Vieira et al. (2010) & $\begin{array}{l}\text { Um estudo exploratório sobre colaboração logística em um grande varejo } \\
\text { supermercadista }\end{array}$ \\
\hline Silveira; Resende (2010) & $\begin{array}{l}\text { Estratégias de mercado no agronegócio paranaense: soja convencional vs. } \\
\text { Transgênica }\end{array}$ \\
\hline $\begin{array}{l}\text { Silva; Severiano Filho } \\
(2011)\end{array}$ & $\begin{array}{l}\text { Ocorrência de custos ocultos em operações de serviços: insights sobre observação } \\
\text { em uma sociedade de economia mista no Brasil }\end{array}$ \\
\hline Lopes et al. (2011) & $\begin{array}{l}\text { Características das transações do etanol carburante entre distribuidoras e } \\
\text { revendedores }\end{array}$ \\
\hline Hamad; Gualda (2011) & $\begin{array}{l}\text { Modelagem de redes logísticas com custos de inventário calculados } \\
\text { a partir da cobertura de estoque }\end{array}$ \\
\hline Perucia et al. (2011) & $\begin{array}{l}\text { Coordenação das atividades produtivas na indústria brasileira de jogos eletrônicos: } \\
\text { hierarquia, mercado ou aliança? }\end{array}$ \\
\hline Pereira et al. (2011) & $\begin{array}{l}\text { Comparando flexibilidade no produto, custos e velocidade de desenvolvimento na } \\
\text { indústria da moda chinesa e brasileira }\end{array}$ \\
\hline Wanke (2012) & Quadro conceitual para gestão de estoques: enfoque nos itens \\
\hline Kussano; Batalha (2012) & $\begin{array}{l}\text { Custos logísticos agroindustriais: avaliação do escoamento da soja em grão do } \\
\text { Mato Grosso para o mercado externo }\end{array}$ \\
\hline De Aquino et al. (2012) & $\begin{array}{l}\text { Certificação de fornecimento e custos de transação: resultados do programa } \\
\text { integrado de desenvolvimento e qualificação de fornecedores - prodfor }\end{array}$ \\
\hline Grzebieluckas et al. (2012) & $\begin{array}{l}\text { Environmental accounting and environmental costs: an analysis of the scientific } \\
\text { production from } 1996 \text { to } 2007\end{array}$ \\
\hline Stroieke et al. (2013) & Estado da arte das aplicações de curvas de aprendizado \\
\hline Molina et al. (2013) & $\begin{array}{l}\text { Modelos matemáticos para problemas de dimensionamento de lotes com restrições } \\
\text { de capacidade e custos de transporte }\end{array}$ \\
\hline Alem; Morabito (2013) & $\begin{array}{l}\text { O problema combinado de planejamento da produção e corte de estoque sob } \\
\text { incertezas: Aplicação em fábricas de móveis de pequeno porte }\end{array}$ \\
\hline Leoncine et al. (2013) & Sistemática para apuração de custos por procedimento médico-hospitalar \\
\hline Alvarenga et al. (2014) & $\begin{array}{l}\text { Qualidade e segurança de vegetais minimamente processados: proposta de } \\
\text { estruturas de governança entre os agentes da cadeia e os sinais da qualidade }\end{array}$ \\
\hline
\end{tabular}

\section{Os autores agradecem a CAPES e ao CNPq pelo apoio para a realização da pesquisa.}




\section{Dados dos autores}

Nome completo: Tiago Henrique de Paula Alvarenga

Filiação institucional: Universidade Federal de Santa Catarina

Departamento: Engenharia de Produção e Sistemas

Função ou cargo ocupado: Estudante de Doutorado

Endereço completo para correspondência: Campus Universitário Trindade Caixa Postal 476 Cep: 88.040-900.

Telefones para contato: 48 3721-7025

e-mail: thpalvarenga@hotmail.com

Nome completo: Simone Sartori

Filiação institucional: Universidade Federal de Santa Catarina

Departamento: Engenharia de Produção e Sistemas

Função ou cargo ocupado: Estudante de Doutorado

Endereço completo para correspondência: Campus Universitário Trindade Caixa Postal 476 Cep: 88.040-900.

Telefones para contato: 48 3721-7025

e-mail: simone.sartori@posgrad.ufsc.br

Nome completo: Jairo José Assumpção

Filiação institucional: Universidade Federal de Santa Catarina

Departamento: Engenharia de Produção e Sistemas

Função ou cargo ocupado: Estudante de Doutorado

Endereço completo para correspondência: Campus Universitário Trindade Caixa Postal 476 Cep: 88.040-900.

Telefones para contato: 48 8403-2604

e-mail: jairo.assumpcao@posgrad.ufsc.br

\section{Nome completo: Lucila Maria de Souza Campos}

Filiação institucional: Universidade Federal de Santa Catarina

Departamento: Departamento de Engenharia de Produção e Sistemas

Função ou cargo ocupado: Professora Adjunto

Endereço completo para correspondência: Campus Universitário Trindade Caixa Postal 476 Cep: 88.040-900. 
Telefones para contato: 48 3721-7026

e-mail: lucila.campos@ufsc.br

Submetido em: 10-02-2015

Aceito em: 17-03-2015 